\title{
A PET activation study of dynamic mechanical allodynia in patients with mononeuropathy
}

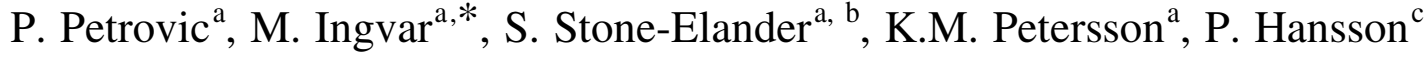 \\ ${ }^{a}$ Clinical Neurophysiology, Department of Clinical Neuroscience, Karolinska Institute, Karolinska Hospital, Stockholm, Sweden \\ ${ }^{\mathrm{b}}$ Karolinska Pharmacy, Karolinska Institute, Karolinska Hospital, Stockholm, Sweden \\ ${ }^{\mathrm{c}}$ Neurogenic Pain Unit, Multidisciplinary Pain Center and Department of Rehabilitation Medicine, Karolinska Institute, Karolinska Hospital, \\ Stockholm, Sweden
}

Received 28 September 1998; received in revised form 27 May 1999; accepted 8 June 1999

\begin{abstract}
The objective of this study was to investigate the central processing of dynamic mechanical allodynia in patients with mononeuropathy. Regional cerebral blood flow, as an indicator of neuronal activity, was measured with positron emission tomography. Paired comparisons were made between three different states; rest, allodynia during brushing the painful skin area, and brushing of the homologous contralateral area. Bilateral activations were observed in the primary somatosensory cortex (S1) and the secondary somatosensory cortex (S2) during allodynia compared to rest. The S1 activation contralateral to the site of the stimulus was more expressed during allodynia than during innocuous touch. Significant activations of the contralateral posterior parietal cortex, the periaqueductal gray (PAG), the thalamus bilaterally and motor areas were also observed in the allodynic state compared to both non-allodynic states. In the anterior cingulate cortex (ACC) there was only a suggested activation when the allodynic state was compared with the non-allodynic states. In order to account for the individual variability in the intensity of allodynia and ongoing spontaneous pain, rCBF was regressed on the individually reported pain intensity, and significant covariations were observed in the ACC and the right anterior insula. Significantly decreased regional blood flow was observed bilaterally in the medial and lateral temporal lobe as well as in the occipital and posterior cingulate cortices when the allodynic state was compared to the non-painful conditions. This finding is consistent with previous studies suggesting attentional modulation and a central coping strategy for known and expected painful stimuli. Involvement of the medial pain system has previously been reported in patients with mononeuropathy during ongoing spontaneous pain. This study reveals a bilateral activation of the lateral pain system as well as involvement of the medial pain system during dynamic mechanical allodynia in patients with mononeuropathy. C) 1999 International Association for the Study of Pain. Published by Elsevier Science B.V.
\end{abstract}

Keywords: Positron emission tomography; Regional cerebral blood flow; Brain activation; Pain; Painful mononeuropathy; Dynamic mechanical allodynia

\section{Introduction}

Pain is a complex phenomenon involving sensory-discriminative, cognitive-evaluative and affective-motivational dimensions, which are processed in parallel (Melzack and Casey, 1968). It is currently believed that the lateral pain system is more involved in sensory-discriminative aspects of pain processing whereas the medial system is more involved in processing the affective-motivational component (Albe-Fessard et al., 1985; Vogt et al., 1993; Willis, 1995). Functional neuroimaging studies have identified

* Corresponding author. Section of Clinical Neurophysiology, Department of Clinical Neuroscience, Karolinska Hospital, 17176 Stockholm, Sweden. Tel.: +46-8-5177-5134; fax: +46-8-344-146.

E-mail address: martini@neuro.ks.se (M. Ingvar) several networks, which are involved in pain processing in man. Acute phasic noxious stimulation has been used in most of these studies. Apart from some inconsistencies, there is a general consensus that such stimuli activate the anterior cingulate cortex (ACC) and the mid-/anterior insula of the medial pain system as well as the primary- and secondary somatosensory cortices (S1 and S2) of the lateral pain system (Jones et al., 1991; Talbot et al., 1991; Casey et al., 1994, 1996; Coghill et al., 1994; Apkarian, 1995; Davis et al., 1995, 1997; Hsieh, 1995; Vogt et al., 1996). These findings support the hypothesis that the experience of pain is processed in a parallel interactive and distributed fashion.

The pathophysiology of neuropathic pain due to peripheral nerve injury is not completely understood (Bennett, 1994). The peripheral nerve lesion may result in different clinical manifestations such as spontaneous ongoing pain 
and, in a minority of cases, allodynia (Hansson and Kinnman, 1996). The most common type of allodynia is pain due to a light dynamic mechanical stimulus (Hansson and Kinnman, 1996). We have previously reported changes in regional cerebral blood flow (rCBF) following the alleviation of pain in patients suffering from ongoing spontaneous pain due to chronic painful mononeuropathy (Hsieh et al., 1995a). Increased activity of the ACC and the anterior insula of the medial pain system were observed during spontaneous ongoing pain, which suggests an increased tone in the affective-motivational dimension of the pain experience. In accordance with other positron emission tomography (PET) studies of ongoing neuropathic pain, we also observed a decreased activity in the thalamus contralateral to the painful neuropathy (Di Piero et al., 1991; Iadarola et al., 1995). However, altered activity of the primary or secondary somatosensory cortex has not been reported in studies of ongoing neuropathic pain.

The objective of the present study was to examine the central processing of allodynia evoked by a dynamic mechanical stimulus. Dynamic mechanical allodynia is usually said to have an explosive, non-physiological character, which is often accompanied by aftersensations (Hansson, 1994). Affective and sometimes vegetative responses are reported during allodynia. Clinical and experimental data suggest that dynamic mechanical allodynia involves activation of low threshold A-beta mechanoreceptive afferents (A $\beta$-fibres) (Gracely et al., 1992; Bennett, 1994). Several possible pathophysiological mechanisms have been disclosed; e.g. peripheral crosstalk between $\mathrm{A} \beta$-fibres and nociceptive fibres, opening of previously silent synapses in the spinal cord bridging the mechanoreceptive and the nociceptive system, sprouting of mechanoreceptive fibres in the dorsal horn to establish new synaptic connections between the large fibre system and nociceptive neurons, and sensitization of spinal dorsal horn neurons (Hansson and Kinnman, 1996). Thus, dynamic mechanical allodynia is likely to be composed by signals reaching the brain from both the nociceptive- and the mechanoreceptive systems. Therefore, we hypothesized that the activation of the primary somatosensory cortex would be more expressed during the allodynic experience than during a non-painful tactile sensation elicited by the same stimulus outside the allodynic area. We also hypothesized that tactile allodynia would activate the medial pain system reflecting the affective component of the painful experience.

\section{Methods}

\subsection{Patients}

Five patients with mononeuropathy and dynamic mechanical allodynia in the lower extremity participated in the study (Table 1). The patients were included if they had had at least a 6-month period of a lower extremity mononeuropathy and dynamic mechanical allodynia following a peripheral nerve lesion, with or without ongoing spontaneous pain. The allodynic experience had to be reproducible in clinical testing regarding intensity without any significant habituation during brushing for $60 \mathrm{~s}$.

As described in Table 1, three of the patients had rightsided mononeuropathy and two had left-sided mononeuropathy. Two of the patients also reported spontaneous ongoing pain (one with a right-sided nerve-lesion and one with a left-sided nerve-lesion). One patient was on medication (see Table 1) during the study. They were all righthanded (Edinburgh handiness inventory) and reported no history of major psychiatric disorder or head trauma. None fulfilled the criteria for depression although one was in the border zone according to MADRS depression inventory (Montgomery and Åsberg, 1979). The local Ethics and Radiation safety committees at the Karolinska Hospital approved all procedures. Informed consent was given by all the subjects.

\subsection{PET scanning}

Repeated measurements of rCBF (12 scans/subject, 4 scans/state) were made using an Ecat Exact HR PET scanner in 3D-sampling mode and $500 \mathrm{MBq}$ bolus injections of $\left[{ }^{15} \mathrm{O}\right]$ butanol producing $60 \mathrm{~s}$ tracer uptake images (Berridge et al., 1990; Ingvar et al., 1994; Wienhard et al., 1994). Scatter correction was performed and a 2D-transmission scan was used for attenuation correction. To ensure that the radioactivity levels in the subjects had returned to background before starting a new scan, at least 10 min elapsed between successive scans. Individual plaster head support was made for each patient to minimize head movements during the PET imaging (Bergström et al., 1981).

\subsection{Experimental design}

The patients were scanned in three different conditions (eyes closed):

Table 1

Clinical characteristics of the patients with mononeuropathy and dynamic mechanical allodynia included in this study

\begin{tabular}{llllllll}
\hline Patient & Age & Sex & Injured nerve & Etiology & Duration (years) & Spontaneous ongoing pain & Treatment \\
\hline MCL & 28 & M & Left sup. Peroneal & Traumatic/ Surgical & 2 & No & None \\
LW & 42 & F & Left Sural & Entrapment/Surgical & 7 & Yes & Ketobemidon \\
DS & 27 & M & Right Femoral/Saphenus & Traumatic & 6 & No & None \\
YZ & 47 & F & Right Saphenus & Surgical & 4 & No & None \\
MC & 58 & F & Right Cut. Fem. Lat. & Surgical & 6 & Yes & None \\
\hline
\end{tabular}


1. Reference condition in which the patients were lying still and were instructed to relax and not to think or do anything in particular but relax (Rest).

2. Brush stimuli were induced by lightly stroking of the allodynic skin with a soft camel hair brush with a diameter of $0.5 \mathrm{~cm}$ (Allodynia). The stimulation was performed with a rate of approximately 1 stroke/s. It began immediately following the injection of the flow tracer and stopped $45 \mathrm{~s}$. later.

3. Brush stimuli as above on the contralateral homologous area to the allodynic region (Contralateral touch).

These states were scanned in the order: A-B-A-C-B-C-CB-C-A-B-A. Prior to each scan the patients were informed which condition to expect. The subjects were instructed to use a numerical rating scale in which 100 equals the highest imaginable total pain intensity and 0 no pain at all. After each allodynic period the patients were asked to verbally rate the maximum total pain intensity during provocation. If present, they also rated the pain intensity of the spontaneous ongoing pain immediately before each scan. Following the final scan the subjects were interviewed in detail about the sessions and their pain ratings were reviewed and confirmed.

\subsection{Data analysis}

In order to analyze all subjects as a group, the PET images of the two patients with left-sided mononeuropathy were mirrored across the midline. In addition, the data were analyzed separately for the three patients with right-sided nerve lesions and for the two patients with left-sided nerve lesions to compare the results with the group analysis. The PET images were realigned, spatially normalized and transformed into an approximate Talairach-Tournoux stereotactic space (Talairach and Tournoux, 1988), 3D Gaussian filtered $(\mathrm{FWHM}=16 \mathrm{~mm})$ and proportionally scaled to account for global confounders using the SPM95 (Friston et al., 1995). The coordinates of local maxima refer to the approximate Talairach-Tournoux space. The anatomical designations used below refer to the Karolinska Computerized Brain Atlas (Greitz et al., 1991).

The data analysis was performed in three steps. First, the contrasts Allodynia - Rest, Allodynia - Contralateral touch, Rest - Allodynia, Contralateral touch - Allodynia and Contralateral touch - Rest were analyzed, using a multisubject with replications design (3 conditions, 5 blocks (subjects)). The $\mathrm{rCBF}$ increases were investigated in a pre-defined pain network based on previous functional imaging studies of pain (Di Piero et al., 1991, 1994; Jones et al., 1991; Talbot et al., 1991; Apkarian et al., 1992, 1995; Casey et al., 1994, 1996; Coghill et al., 1994; Davis et al., 1995; Drevets et al., 1995; Hsieh, 1995; Hsieh et al., 1995a,b; Iadarola et al., 1995; Craig et al., 1996; Vogt et al., 1996). The pain network included the contralateral S1 and, bilaterally, the thalamus, S2, insula, ACC and the periaqueductal gray (PAG). Similarly, the contralateral S1 and
S2 were chosen for the innocuous somatosensory control condition based on previous functional imaging studies of non-painful vibratory sensibility (Fox et al., 1987; Burton et al., 1993; Coghill et al., 1994). The location of the secondary somatosensory cortex (S2) has been defined anatomically in the dorsal bank of the lateral sulcus in the parietal operculum of the monkey (Roberts and Akert, 1963). This corresponds to the part of BA43/40 which is situated in the human operculum, and functional activations in these regions during pain studies have been regarded as S2 activations (Talbot et al., 1991). Activations in the predefined regions were considered significant if $Z \geq 3.09$ (or $P \leq 0.001$, uncorrected). In addition, a global search was performed and activations containing significant local maxima $(P \leq 0.05$, corrected for multiple non-independent comparisons) that were not part of the pre-defined pain matrix are given in Tables 4 and 5 .

Finally, in order to investigate whether allodynia provokes a more expressed activation in S1 compared to an identical tactile stimulation of the skin contralateral to the allodynic area, we placed a spherical ROI with a diameter of $5 \mathrm{~mm}$ in the postcentral gyrus contralateral to the respective site of stimulation. The exact positioning of the ROIs was guided by the regional analysis of the activation in the right postcentral gyrus evoked by the non-painful stimulation condition (see Fig. 3). At this site, the ROI representing innocuous touch $\left(\mathrm{S}_{\text {right }}\right)$ was chosen and the corresponding contralateral region $\left(S 1_{\text {left }}\right)$, representing the allodynia, was chosen by mirroring the ROI across the midline. A two factor ANOVA (with subject and state as independent variables) was then performed between the increases in rCBF due to allodynia in the left S1 ROI $\left(\mathrm{S} 1_{\text {leftallodynia }}-\mathrm{S} 1_{\text {leftrest }}\right)$ and the increases in $\mathrm{rCBF}$ due to

\section{Pain intensity ratings (mm VAS)}

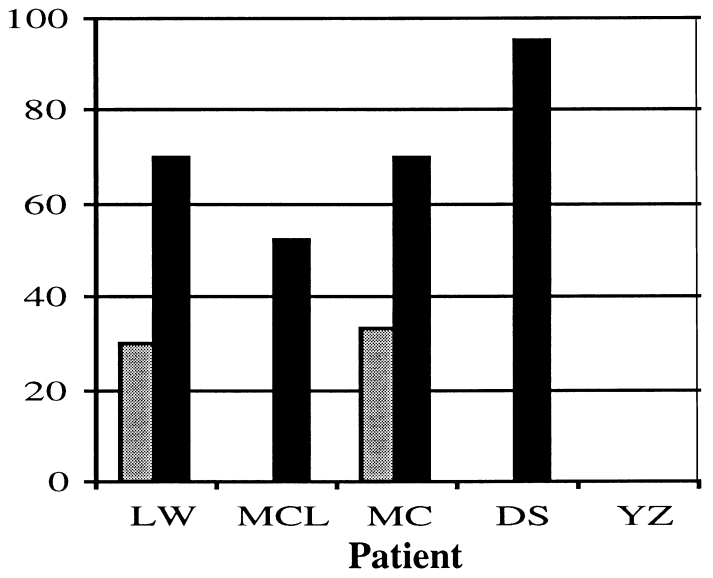

Fig. 1. Pain intensity ratings representing the allodynic and the non-allodynic contrasts. One of the patients $(Y Z)$ failed to rate the pain. Grey bars: Spontaneous ongoing pain immediately before the scannings of the nonallodynic states (mean of 8 ratings). Black bars: Maximum pain during the scannings of the allodynic states (mean of 4 ratings). 
Table 2

Increases in rCBF during allodynia for the group of patients with mononeuropathy (the data were mirrored for the patients with left-sided pain). The search volume was restricted to the predefined pain matrix ${ }^{a}$

\begin{tabular}{|c|c|c|c|c|}
\hline & $X Y Z$-coordinates & $Z$-score & & rCBF-increase $(\%)$ \\
\hline \multicolumn{5}{|l|}{ Thalamus } \\
\hline \multicolumn{5}{|l|}{ Thalamus sin } \\
\hline Allodynia vs. Rest: & $-10,-22,4$ & 3.83 & $\mathrm{~S}$ & 3.4 \\
\hline Allodynia vs. Contralateral Touch: & $-12,-20,4$ & 4.53 & $\mathrm{~S}$ & 4.1 \\
\hline \multicolumn{5}{|l|}{ Thalamus $d x$} \\
\hline Allodynia vs. Rest: & $8,-22,4$ & 3.39 & $\mathrm{~S}$ & 3.2 \\
\hline Allodynia vs. Contralateral Touch: & $8,-20,4$ & 3.70 & $\mathrm{~S}$ & 3.5 \\
\hline \multicolumn{5}{|l|}{ Lateral pain system } \\
\hline \multicolumn{5}{|l|}{$S 1 \sin$} \\
\hline \multirow[t]{2}{*}{ Allodynia vs. Rest: } & $-16,-44,56$ & 6.89 & $\mathrm{~S}$ & 9.0 \\
\hline & $-22,-50,52$ & 6.83 & $\mathrm{~S}$ & 7.3 \\
\hline \multirow[t]{2}{*}{ Allodynia vs. Contralateral Touch: } & $-16,-44,56$ & 7.03 & $\mathrm{~S}$ & 9.3 \\
\hline & $-20,-50,52$ & 6.23 & $\mathrm{~S}$ & 6.7 \\
\hline \multicolumn{5}{|l|}{$S 2 \sin$} \\
\hline Allodynia vs. Rest: & $-54,-38,20$ & 5.14 & $\mathrm{~S}$ & 5.4 \\
\hline Allodynia vs. Contralateral Touch: & $-54,-36,20$ & 3.47 & $\mathrm{~S}$ & 3.3 \\
\hline \multicolumn{5}{|l|}{$S 2 d x$} \\
\hline \multirow[t]{2}{*}{ Allodynia vs. Rest: } & $42,-36,16$ & 4.01 & $\mathrm{~S}$ & 2.2 \\
\hline & $54,-42,20$ & 3.82 & $\mathrm{~S}$ & 3.7 \\
\hline Allodynia vs. Contralateral Touch: & -- & -- & & \\
\hline \multicolumn{5}{|l|}{ Medial pain system } \\
\hline \multicolumn{5}{|l|}{ Anterior insula sin } \\
\hline Allodynia vs. Rest: & -- & -- & & \\
\hline Allodynia vs. Contralateral Touch: & -- & -- & & \\
\hline \multicolumn{5}{|l|}{ Anterior insula $d x$} \\
\hline Allodynia vs. Rest: & $30,16,4$ & 2.96 & & 2.2 \\
\hline Allodynia vs. Contralateral Touch: & $36,12,4$ & 1.73 & & 1.2 \\
\hline \multicolumn{5}{|l|}{$A C C(B A 32 / 24)$} \\
\hline Allodynia vs. Rest: & $-6,14,32$ & 2.58 & & 2.0 \\
\hline \multirow[t]{2}{*}{ Allodynia vs. Contralateral Touch: } & $-10,12,28$ & 3.22 & $\mathrm{~S}$ & 2.9 \\
\hline & $-2,16,32$ & 3.18 & $\mathrm{~S}$ & 2.1 \\
\hline \multicolumn{5}{|l|}{ PAG/brainstem } \\
\hline Allodynia vs. Rest: & $\begin{array}{l}\text { Significant activation } \\
\text { without any peak } \\
\text { activated voxel }\end{array}$ & & & \\
\hline Allodynia vs. Contralateral Touch: & $4,-26,-4$ & 3.75 & $\mathrm{~S}$ & 3.2 \\
\hline
\end{tabular}

\footnotetext{
${ }^{a}$ The locations of the maximally activated voxels are given in the coordinates of the Talairach-Tournoux atlas (Talairach and Tournoux, 1988). The search for the exact location of the maximal activation was performed in the CBA atlas (Greitz et al., 1991). S = Significant activation. ACC = Anterior cingulate cortex. PAG = Periaqueductal gray. S1 = Primary somatosensory cortex. S2 = Secondary somatosensory cortex.
}

non-painful touch in the right $\mathrm{S} 1 \mathrm{ROI}$ $\left(\mathrm{S} 1_{\text {righttouch }}-\mathrm{S} 1_{\text {rightrest }}\right)$. Adjusted rCBF data for the ROIs were used for this analysis.

\section{Results}

\subsection{Behavioral results}

In spite of instructions to try to avoid movements all but one patient were unable to control minor muscular activity in the extremities and face when the allodynic area was brushed. This movement was observed as occasional muscle contractions of the extremities and in the face during allodynia. All patients rated the maximum total pain intensity as being greater than $50 / 100 \mathrm{~mm}$ during the painful brushing except for the patient who verbally failed to report the pain intensity (Fig. 1). They also reported brush-evoked pain only from the site of stimulation. Only two of the patients reported spontaneous ongoing pain. Due to technical problems, the heart rate of two patients could not be continuously monitored. For the remaining three patients the heart-rate during the scans increased significantly in the allodynic state compared to the other two states (mean 


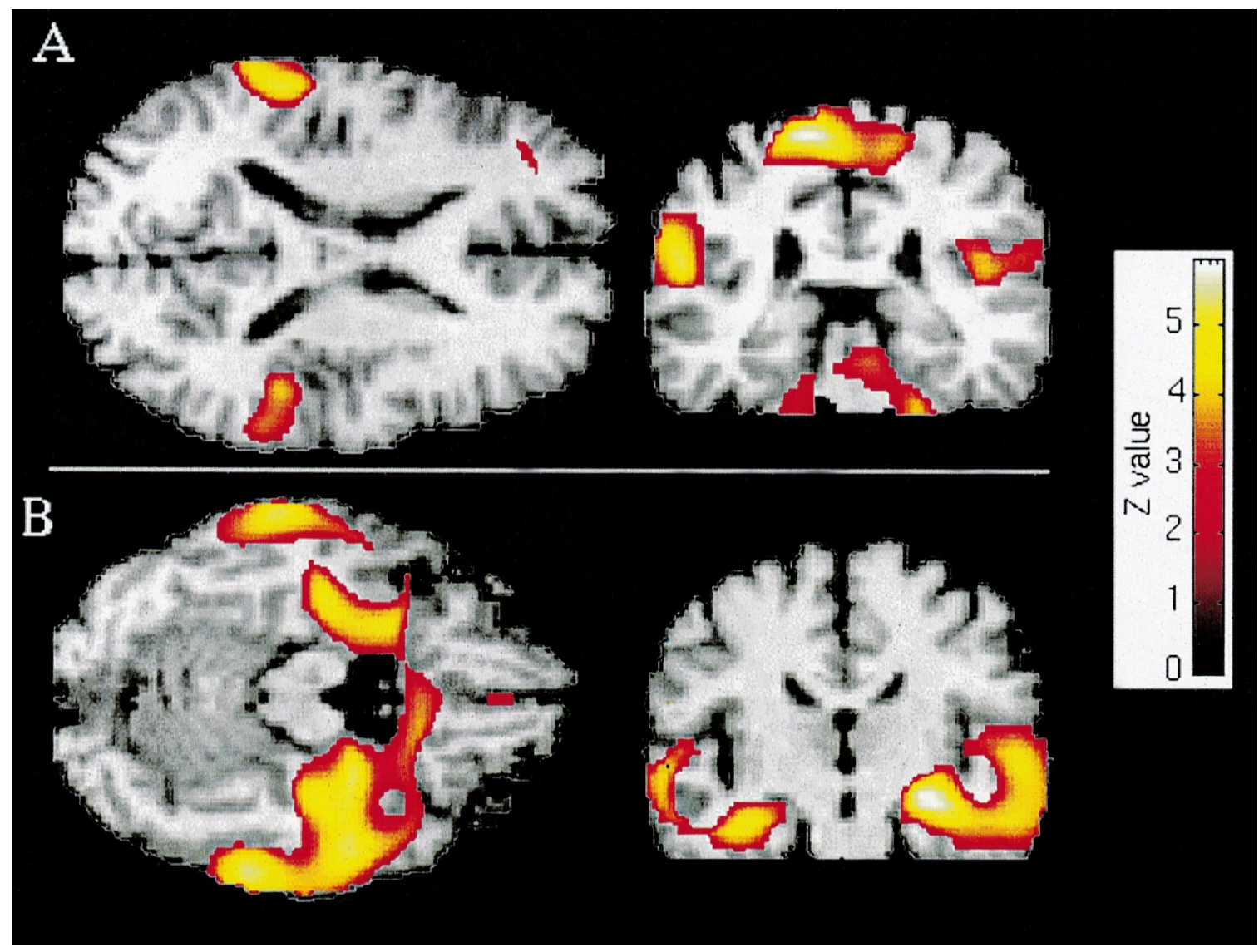

Fig. 2. (A) SPM (Statistical parametric mapping) results of increased $\mathrm{rCBF}$ in the S1, the S2, the brainstem and the cerebellum during Allodynia vs. Rest. Although there was a contralateral dominance, the activation was bilateral. (B) SPM results of decreased activity bilaterally in the medial temporal lobe and lateral temporal regions during Allodynia vs. Contralateral touch. All the data were thresholded at uncorrected $P$-value $=0.01$. The images are shown in neurological convention; left is left and right is right in the coronal section and the horizontal section is shown from above.

heart-rate during allodynia $=74.12$; mean heart-rate during conterlateral touch $=63.26$; mean heart-rate during rest $=61.14$; assessed by two factor ANOVA with state and subject as independent variables; $P$-value $<0.0001$; $\left.F_{1,27}=133.4\right)$.

\subsection{Results of the search in the predefined matrix}

Activations of the lateral pain system (with 9\% rCBF increase in the contralateral S1) and the thalamus bilaterally were observed during allodynia (Table 2; Fig. 2A). No significant activation was found in the ACC or the anterior insula of the medial pain system when the allodynic state was compared to the non-allodynic states except for an ACC activation just above the significance level in the contrast Allodynia - Contralateral touch. Non-painful touch activated a mirror site to one of the allodynia-induced maxima in the S1 and also activated the contralateral S2 (Table 3).

Allodynia provocation and contralateral touch evoked activations in mirror sites in the $\mathrm{S} 1$, as anatomically defined

Table 3

Increases in rCBF during non-painful brushing for the group of patients with mononeuropathy (the data were mirrored for the patients with left-sided pain). The search volume was restricted to S1 and S2 contralateral to the stimulated leg ${ }^{\mathrm{a}}$

\begin{tabular}{|c|c|c|c|c|}
\hline & $X Y Z$-coordinates & $Z$-score & & rCBF increase $(\%)$ \\
\hline \multicolumn{5}{|l|}{$\mathrm{S} 1 \mathrm{dx}$} \\
\hline Contralateral Touch vs. Rest: & $14,-52,48$ & 3.20 & $S$ & 2.4 \\
\hline \multicolumn{5}{|l|}{$\mathrm{S} 2 \mathrm{dx}$} \\
\hline Contralateral Touch vs. Rest: & $42,-36,12$ & 4.15 & S & 2.2 \\
\hline
\end{tabular}

${ }^{a}$ The locations of the maximally activated voxels are given in the coordinates of the Talairach-Tournoux space (Talairach and Tournoux, 1988). The search for the exact location of the maximal activation was performed in the CBA atlas (Greitz et al., 1991). S = Significantactivation. S1 = Primary somatosensory cortex. S2 = Secondary somatosensory cortex. 


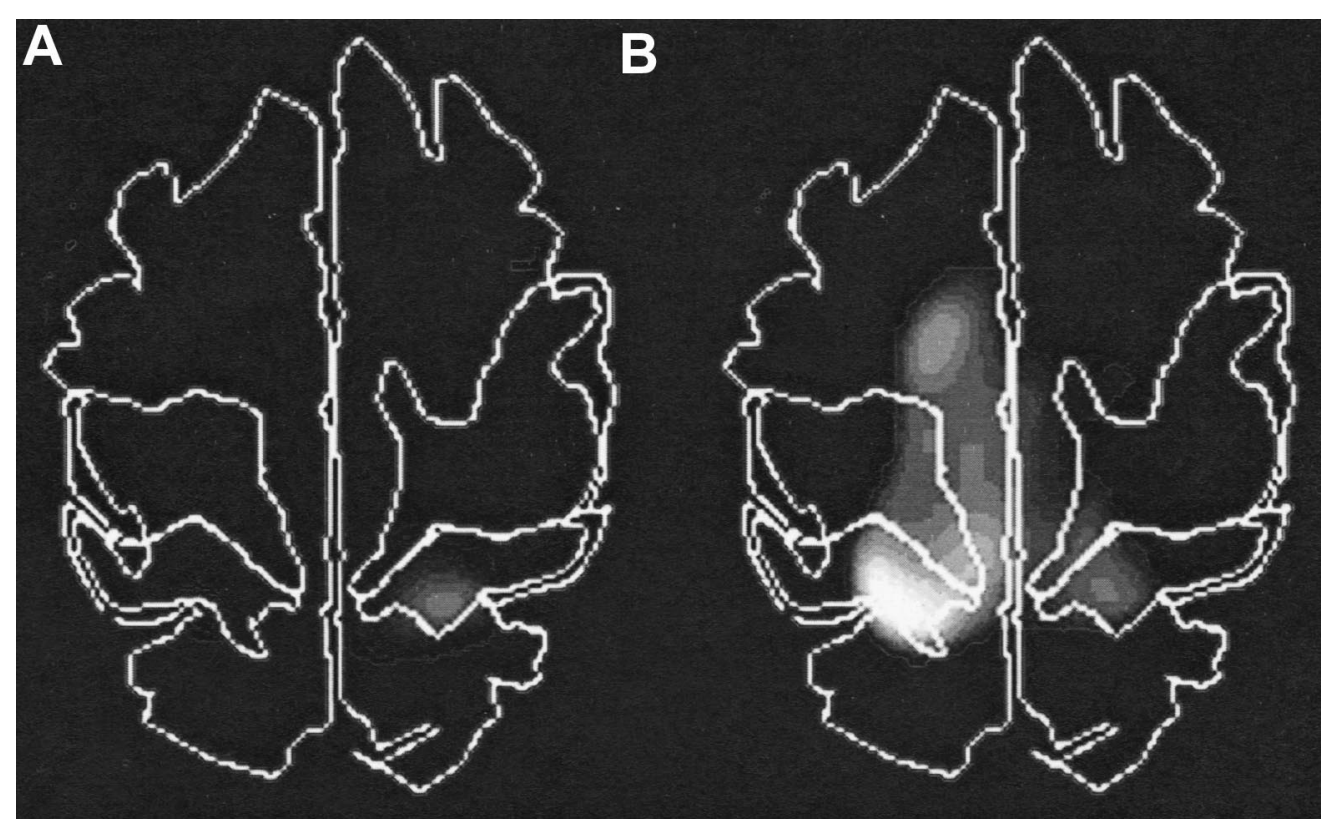

Fig. 3. (A) Increased rCBF in the postcentral gyrus (S1) during Contralateral touch vs. Rest shown in the CBA (thresholded at uncorrected $P$-value $=0.05$ ). (B) Increased $\mathrm{rCBF}$ in the postcentral region (S1) and motor regions during Allodynia vs. Rest shown in the CBA (thresholded at uncorrected $P$-value $=0.001)$. The activity in the sensory-motor cortex was most expressed in the contralateral postcentral gyrus with the maximum corresponding to the contralateral activity induced by innocuous touch. Note that the activity is also present in the ipsilateral postcentral gyrus. The images are shown in neurological convention; the horizontal section is shown from above.

by the CBA (Fig. 3). The allodynic activation was situated deep in the medial-dorsal parts of the left postcentral gyrus (S1), most extensively within the borders of this gyrus but also extending into the left pre-central gyrus (M1).

\subsection{Additional rCBF-changes in the global search}

All additional changes in rCBF during allodynia revealed by the SPM analysis are presented in Tables 4 and 5, and Fig. 2. The ipsilateral S1 was also activated during the allodynic state vs. rest, although the most intensely elicited sites were contralateral to the stimulation. Activations were also observed in various motor regions, although no local maximum was observed in the primary motor cortex. Bilaterally deactivated areas included the medial temporal lobe, the lateral temporal lobe and the posterior occipital lobe.

\subsection{Regional SI ANOVA}

The rCBF increase was more expressed during allodynia than during touch in the corresponding contralateral somatotopic S1 ROI (7.1\% vs. $2.5 \%)$. This difference was significant for the five subjects when tested by two factor ANOVA between the increases due to non-painful touch in the right $\mathrm{S} 1 \mathrm{ROI}$ and the increases due to allodynia in the left S1 ROI $\left(P\right.$-value $\left.<0.0003 ; F_{1.30}=17.2\right)$.

\subsection{Separate analyses of the left- and right mononeuropathy-sided patients}

During allodynia, increased activity was found bilaterally in S1 and S2 of the lateral pain system and also in the contralateral thalamus for the left- and right- sided mononeuropathy patients. Decreased activity was observed bilaterally in the medial temporal lobe, the occipital cortex and the lateral temporal lobe for both groups. These results for the two subgroups are in agreement with those from the group analysis of all five patients (data available upon request).

\section{Discussion}

This paper deals with dynamic mechanical allodynia, i.e. pain due to normally non-painful touch, in patients with mononeuropathy. The patients included in this study were carefully matched, which is of importance when averaging the results across subjects. The group results obtained from mirroring the data of the two patients with left-sided lesions must, however, be interpreted with some caution, i.e. only general conclusions can be made about the activations outside the predefined pain matrix. However, the same pattern of activations and deactivations were also revealed by the separate analyses of the patients with left- and rightsided mononeuropathy. The rCBF changes revealed by the group and subgroup analyses were predominantly bilateral. There is, of course, a possibility that the mirroring process may mask unilateral rCBF changes.

It is our experience that for most patients with clinically significant tactile allodynia it is impossible to suppress all movements during provocation. To reduce the number of 
Table 4

Additional increases in $\mathrm{rCBF}$ outside the predefined pain network during allodynia for the group of patients with mononeuropathy (the data were mirrored for the patients with left-sided pain) ${ }^{\mathrm{a}}$

\begin{tabular}{|c|c|c|c|}
\hline & $X Y Z$-coordinates & $Z$-scores & $\begin{array}{l}\text { Corrected } \\
P \text {-value }\end{array}$ \\
\hline \multicolumn{4}{|l|}{ Allodynia vs. Rest } \\
\hline \multicolumn{4}{|c|}{$S M C / P M C / S M A / P P C$} \\
\hline BA7 sin & $-26,-52,48$ & 5.73 & 0.000 \\
\hline BA6 sin & $-14,-8,52$ & 5.22 & 0.000 \\
\hline $\mathrm{S} 1 \mathrm{dx}$ & $14,-48,52$ & 4.57 & 0.009 \\
\hline \multicolumn{4}{|c|}{ Cerebellum/Thalamus } \\
\hline Cerebellum sin & $-30,-50,-28$ & 5.73 & 0.000 \\
\hline Vermis & $0,-60,-12$ & 5.29 & 0.000 \\
\hline Cerebellum dx & $30,-50,-28$ & 4.92 & 0.002 \\
\hline \multicolumn{4}{|l|}{ Allodynia vs. } \\
\hline \multicolumn{4}{|c|}{ Contralateral Touch } \\
\hline \multicolumn{4}{|c|}{$P M C / S M A$} \\
\hline BA $6 \sin$ & $-12,-6,52$ & 5.45 & 0.000 \\
\hline \multicolumn{4}{|c|}{ Cerebellum/Thalamus } \\
\hline Vermis & $-2,-60,-12$ & 6.62 & 0.000 \\
\hline Cerebellum sin & $-28,-54,-28$ & 5.79 & 0.000 \\
\hline Cerebellum dx & $32,-46,-28$ & 5.24 & 0.000 \\
\hline Cerebellum dx & $34,-66,-28$ & 4.38 & 0.018 \\
\hline
\end{tabular}

${ }^{\mathrm{a}}$ The locations of the maximally activated voxels are given in the coordinates of the Talairach-Tournoux space (Talairach and Tournoux, 1988). The search for the exact location of the maximal activation was performed in the CBA atlas (Greitz et al. 1991). PMC = Premotor cortex. PPC = Posterior parietal cortex. SMA $=$ Supplementary motor areas. $\mathrm{S} 1=$ Primary somatosensory cortex.

motor activations to a minimum the subjects were told to try to avoid movements during the stimulation. However, occasional muscular activity was observed in all but one of the patients during the scanning period. Separating movement related activations from pain related activations is a potential problem in all functional imaging studies of pain since any observed movement or unobserved muscle tension may activate the postcentral gyrus in concert with the motor cortex (Colebatch et al., 1991; Hsieh et al., 1995b). In addition, movement intention/preparation may increase the activity in the motor cortex (Hsieh et al., 1994; Deiber et al., 1996). The same potential problem applies to S2 since movement may activate this region (Weiller et al., 1996). Movement related activity in the somatosensory regions is not static or simply additive. Passive movements activate S2 significantly more than active movements (Weiller et al., 1996). The activity in these regions is also dependent on which sensory channel is attended (Ghatan et al., 1995; Shulman et al., 1997; Blakemore et al., 1998; Petrovic et al., 1998). Thus, it is not known how, or if, movement interacts with intense pain in $\mathrm{S} 1$ or $\mathrm{S} 2$ when attention is directed to the painful stimulus. However, there are several factors suggesting that the activation in the postcentral gyrus was mainly related to a sensory response to allodynia.

First, the most expressed activation of the sensory-motor cortex was located in the postcentral gyrus on the border to the posterior parietal cortex, extending into the motor cortex
(Fig. 3). There was no local maximum in the pre-central region. In comparison, in recent studies of motor activity there are local maxima in the pre-central region or in the central sulcus (Dettmers et al., 1995; Stephan et al., 1995; Fink et al., 1997).

Secondly, the extensive S1-activation during allodynia had one maximum at an almost identical but contralateral coordinate as compared to the non-painful stimulation ( 22, - 50, 52 during Allodynia vs. Rest and 14, - 52, 48 during Touch vs. Rest; Fig. 3). This suggests that the activations stem from the same peripheral site.

Thus, we conclude that the increased S1 activity during allodynia pertains primarily to the allodynic response but observable or unobservable motor activity can not be completely disregarded as a factor in the activity increase. This problem is shared with most studies of pain where subjects are awake and conscious (Coghill et al., 1994; Casey et al., 1996; Rainville et al., 1997; Peyron et al., 1998). To resolve this uncertainty, future studies need to investigate this possible confound with, e.g. electromyography (EMG).

Soft brushing on the non-allodynic side provoked a nonpainful, low-intensity tactile sensation. In the regional analysis of increases during innocuous touch, activations of the contralateral S1 and S2 were observed, which is in agreement with previous PET studies of somatotactile sensation (Fox et al., 1987; Burton et al., 1993; Coghill et al., 1994).

Brushing the allodynic region provoked an acute painful sensation in the leg with a maximum total pain intensity which the patients rated between 50-100/100 mm. Significant bilateral activations of S1 and S2 were observed during the allodynic state compared to the habitual state. The ROI analysis of the S1 confirmed that the activation during the allodynic sensation was significantly more expressed than the activations during non-painful touch sensation provoked by the same stimulus but in the opposite leg (7.1\% vs. $2.5 \%$ rCBF increase).

Neurons responding to noxious stimuli have been found in the primary and secondary somatosensory cortex of primates (Robinson and Burton, 1980a; Kenshalo and Isensee, 1983; Dong et al., 1989). A study of primates with a damaged primary somatosensory cortex and a case report of a patient with a tumor affecting the secondary somatosensory cortex have revealed clear deficits in pain discrimination (Kenshalo et al., 1991; Greenspan and Winfield, 1992) which supports the hypothesis that the lateral pain system plays an important role in the sensory/discriminative aspects of pain processing (Kenshalo et al., 1980; Kenshalo and Isensee, 1983; Albe-Fessard et al., 1985; Chung et al., 1986; Friedman and Murray, 1986; Vogt et al., 1993; Apkarian and Shi, 1994; Willis, 1995). Several functional imaging studies of phasic heat pain, tonic pain and electrically induced pain support the involvement of S1, S2 and the thalamus in pain processing (Talbot et al., 1991; Casey et al., 1994; Coghill et al., 1994; Hsieh, 1995; Casey et al., 
Table 5

Decreases in $\mathrm{rCBF}$ during allodynia for the group of patients with mononeuropathy (the data were mirrored for the patients with left-sided pain) ${ }^{\mathrm{a}}$

\begin{tabular}{|c|c|c|c|}
\hline & $X Y Z$-coordinates & $Z$-scores & Corrected $P$-value \\
\hline \multicolumn{4}{|c|}{ Rest vs. Allodynia } \\
\hline \multicolumn{4}{|c|}{ Medial temporal lobe $d x /$ Lateral temporal lobe $d x$} \\
\hline Hippocampus dx & $26,-22,-12$ & 5.81 & 0.000 \\
\hline Amygdala/Hippocampus dx & $22,-14,-12$ & 5.74 & 0.000 \\
\hline Superior TG (BA38) dx & $44,-8,-12$ & 4.96 & 0.002 \\
\hline Middle TG (BA21) dx & $56,-46,-12$ & 4.90 & 0.002 \\
\hline Heschl's G/Planum temp (BA41/42) dx & $54,-16,4$ & 4.54 & 0.010 \\
\hline \multicolumn{4}{|l|}{ Medial temporal lobe sin } \\
\hline Hippocampal gyrus/Uncus sin & $-36,-20,-20$ & 4.35 & 0.021 \\
\hline Hippocampal gyrus/Uncus sin & $-34,-22,-16$ & 4.33 & 0.02 \\
\hline \multicolumn{4}{|l|}{ Lateral temporal lobe $\sin$} \\
\hline Superior TG/Heschl's G (BA22/41) sin & $-54,-14,-4$ & 4.62 & 0.007 \\
\hline \multicolumn{4}{|l|}{ Occipital lobe $\sin$} \\
\hline BA17/18 sin & $-18,-84,-8$ & 5.00 & 0.001 \\
\hline BA18 sin & $-26,-92,4$ & 4.31 & 0.024 \\
\hline \multicolumn{4}{|l|}{ Occipital lobe/PCC } \\
\hline BA18 dx & $24,-58,4$ & 5.00 & 0.001 \\
\hline PCC (BA29/30) sin & $-14,-48,8$ & 4.89 & 0.002 \\
\hline BA $19 \mathrm{dx}$ & $20,-80,24$ & 4.83 & 0.003 \\
\hline Precuneus (BA31) dx & $18,-66,12$ & 4.42 & 0.016 \\
\hline BA $19 \mathrm{dx}$ & $34,-78,24$ & 4.25 & 0.030 \\
\hline BA $18 / 19 d x$ & $36,-84,-4$ & 4.22 & 0.034 \\
\hline \multicolumn{4}{|c|}{ Contralateral Touch vs. Allodynia } \\
\hline \multicolumn{4}{|c|}{ Medial temporal lobe $d x /$ Lateral temporal lobe $d x / A C C \sin$} \\
\hline Hippocampus/Amygdala dx & $26,-22,-12$ & 6.07 & 0.000 \\
\hline Middle TG (BA21/37) dx & $54,-44,-12$ & 5.37 & 0.000 \\
\hline Middle/Superior TG (BA21/22) dx & $54,-36,0$ & 5.31 & 0.000 \\
\hline Middle/Superior TG (BA21/38) dx & $44,-14,-16$ & 5.21 & 0.000 \\
\hline Heschl's G (BA41) dx & $54,-14,0$ & 4.78 & 0.003 \\
\hline Inferior ACC (BA32) sin & $-4,34,-4$ & 4.16 & 0.042 \\
\hline \multicolumn{4}{|l|}{ Medial temporal lobe sin } \\
\hline Hippocampal gyrus/Uncus sin & $-32,-18,-20$ & 4.84 & 0.003 \\
\hline Hippocampus/Hippocampal gyrus sin & $-30,-20,-16$ & 4.78 & 0.003 \\
\hline Amygdala/Uncus sin & $-22,-2,-16$ & 4.52 & 0.010 \\
\hline \multicolumn{4}{|l|}{ Lateral temporal lobe sin } \\
\hline Middle TG (BA21) sin & $-58,-40,-12$ & 5.47 & 0.000 \\
\hline Superior TG (BA22) sin & $-58,-20,-4$ & 4.24 & 0.031 \\
\hline Superior TG/Heschl's G (BA22/41) sin & $-56,-16,-4$ & 4.18 & 0.04 \\
\hline \multicolumn{4}{|l|}{ Occipital lobe/PCC/Lateral temporal lobe $d x$} \\
\hline PCC/Precuneus (BA23/31) & $6,-56,32$ & 5.22 & 0.000 \\
\hline Middle TG (BA19) dx & $48,-66,20$ & 5.08 & 0.001 \\
\hline BA $19 \mathrm{dx}$ & $34,-78,24$ & 4.62 & 0.007 \\
\hline BA $19 d x$ & $18,-80,28$ & 4.21 & 0.035 \\
\hline BA $19 d x$ & $38,-76,24$ & 4.59 & 0.01 \\
\hline
\end{tabular}

${ }^{a}$ The locations of the maximally activated voxels are given in the coordinates of the Talairach-Tournoux space (Talairach and Tournoux, 1988). The search for the exact location of the maximal activation was performed in the CBA atlas (Greitz et al., 1991). ACC $=$ Anterior cingulate cortex. PCC $=$ Posterior cingulate cortex. $\mathrm{TG}=$ Temporal gyrus.

1996; Craig et al., 1996; Rainville et al., 1997). The studies above indicate that the increased activity in the lateral pain system during allodynia may contribute to the painful experience. It is also likely that extensive activation of S1 and S2 represents a co-activation of the mechanoreceptive and the nociceptive systems, consistent with previous suggestions from the experimental literature (Hansson and Kinnman, 1996). The results of the present study are in line with studies of experimental allodynia and allodynia following Wallenberg infarct where increased activity in S1 and
S2 were observed (Iadarola et al., 1998; Peyron et al., 1998). The extensive activation of the lateral pain system in dynamic mechanical allodynia contrasts with the lack of activation in these regions during spontaneous ongoing pain in patients with mononeuropathy (Hsieh et al., 1995a) as well as in other ongoing neuropathic pain states (Di Piero et al., 1991). The discrepancy may reflect that provoked allodynia represents an acute exacerbation of the pain that enhances the spatial localizing component. The rate of change in pain intensity as a factor determining the 
cortical response may actually be one of the reasons to why there is a such a variability in the pain literature regarding the involvement of S1 and S2 (Apkarian, 1995).

$\mathrm{S} 2$ is a small area defined anatomically in primates as situated in the dorsal banks of the lateral sulcus in the parietal opercular cortex (Roberts and Akert, 1963). Thus, activations of the human operculum in PET studies of pain and other non-painful sensations have been regarded as S2 activations. However, contributions by the more posteriorlateral area involved in somatosensory processing, defined as $7 \mathrm{~b}$ in monkeys, may also contribute to the increased activation (Coghill et al., 1994). The peak activation of the parietal operculum, including S2, was more posteriorly located than in most previously published PET studies of pain in which the stimuli have been induced in the arm (Talbot et al., 1991; Casey et al., 1994, 1996; Coghill et al., 1994; Craig et al., 1996; Rainville et al., 1997). In single neuron recordings of $\mathrm{S} 2$, it has been shown that the foot area is located more posteriorly than the face area in these structures (Robinson and Burton, 1980b). Andersson and coworkers (Andersson et al., 1997) reported increased activity in anterior parts of S2 when painful stimulation of the hand was compared with painful stimulation of the foot. A joint comparison (painful stimulation of the hand and foot vs. baseline) revealed a more posterior activation of the S2. Their results are congruent with our findings and support the existence of a somatotopic organization in S2.

Bilateral responses were observed in the thalamus, S1 and S2 during the allodynic state compared to rest. Only unilateral activation of the $\mathrm{S} 1$ in response to painful stimuli has been reported previously. The activation in the ipsilateral postcentral gyrus during allodynia had almost the same coordinates as the brush-evoked activation, which suggests that the ipsilateral response in S1 is somatotopic. However, pain was always reported only from the stimulated side. The bilateral responses in the primary somatosensory cortex may be mediated by a subgroup of neurons in S1 which normally respond to innocuous stimulation from a defined contralateral receptive field, but also respond to ipsilateral intense noxious stimuli (Kenshalo and Isensee, 1983). We confirm previous observations that the S2 area has a tendency to be activated bilaterally by unilateral painful stimuli (Casey et al., 1994). This is consistent with animal studies of S2 which have indicated bilateral receptive fields of neurons responding to experimental noxious input (Dong et al., 1989).

Several regions with decreased $\mathrm{rCBF}$ during the allodynic state were observed. Decreases in $\mathrm{rCBF}$ are generally regarded as a total net decrease in the neural activity of the involved region (Hsieh, 1995; Raichle, 1997, 1998). In this context it should be noted that the $\mathrm{rCBF}$ is an indirect measure of brain activity and can not separate inhibition from excitation but only measures the net result of neuronal activity. Decreased activity was found in the lateral parts of the temporal lobe bilaterally and in the occipital lobe/posterior cingulate gyrus. These areas are involved in general auditory, language and visuospatial processing (Mazziotta et al., 1982; Ungerleider and Haxby, 1994; Ghatan et al., 1995; Price et al., 1996). A deactivation of such regions may reflect an attention-guided, top-down inhibition of processing of non-attended sensory components (Haxby et al., 1994; Ghatan et al., 1998). Thus, it is suggested that the observed deactivations in these sensory areas, during the allodynic state compared to the non-allodynic states, reflect increased attention towards the processing of allodynia. Bilateral deactivations were also observed in the hippocampus/parahippocampal gyrus, extending into the amygdala/ uncus during the allodynic state. These structures are involved in declarative and emotional memory processing. The amygdala is also involved in behavioral and autonomic emotional response to aversive stimuli (LeDoux, 1993; Squire and Zola, 1996; Petersson et al., 1997). We suggest that these deactivations may represent a coping strategy for handling an acute, but well-known painful situation. The deactivations may reflect a meaningful suppression of brain systems subserving episodic memory and emotional response to aversive stimuli (Hsieh, 1995).

No significant activation was found in the ACC or the mid-anterior insula in the Allodynia vs. Rest comparison (although a significant activation was observed in the ACC during Allodynia vs. Contralateral stimulation). This is consistent with the results from a study of patients with allodynia following Wallenberg infarct (Peyron et al., 1998). Peyron et al. (1998) suggested that the absence of ACC activation could be a specific feature for patients with allodynia after Wallenberg infarct, which may also be the case for allodynia after peripheral nerve damage. The lack of activation in the medial pain system, in contrast to the massive activations in the lateral pain system (7-9\% $\mathrm{rCBF}$ increase in S1), was still an unexpected finding since the patient descriptions of dynamic mechanical allodynia usually include affective components (Hansson, 1994) and since the medial system is considered to be involved in processing the affective and evaluative part of the pain experience (Albe-Fessard et al., 1985; Vogt et al., 1993; Craig et al., 1994; Talbot et al., 1995; Willis, 1995; Rainville et al., 1997).

There were large differences in the total pain intensity ratings during the non-allodynic scans (VAS ratings of spontaneous pain ranging from 0 to $45 \mathrm{~mm}$ ) and during allodynia (VAS ratings ranging from 50 to $100 \mathrm{~mm}$ ). A continuous activation of the medial pain system has been demonstrated in ongoing spontaneous pain (Hsieh et al., 1995a) and the ACC response shows correlation with the subjectively perceived pain intensity and unpleasantness (Davis et al., 1997; Derbyshire et al., 1997; Rainville et al., 1997). The variability of the perceived pain intensity may have been paralleled by a variable response in the medial pain system during both the allodynic and the rest states which may explain the lack of significant activation in these structures when directly comparing the rCBF in the allodynic with the non-allodynic states. Thus, the discre- 
pancy in the activation of the medial pain system between the present PET study of allodynia and several other PET studies of pain (Jones et al., 1991; Talbot et al., 1991; Casey et al., 1994, 1996; Coghill et al., 1994; Hsieh et al., 1995a,b; Craig et al., 1996; Vogt et al., 1996; Rainville et al., 1997; Iadarola et al., 1998) may be due to a heterogeneous patient material in the clinical allodynia study. The same may be the case in the study of Peyron and colleagues (Peyron et al., 1998) since half of the included patients had an ongoing spontaneous pain and displayed a variable response to the induced allodynia.

Previously, a within condition correlation has been observed between the reported unpleasantness of pain and rCBF in the ACC (Rainville et al., 1997). Also, when the rCBF was regressed on the rated pain intensity across conditions a significant correlation was observed in the ACC (Davis et al., 1997; Derbyshire et al., 1997; Silverman et al., 1997). Thus, subjectively perceived pain intensity/ unpleasentness may be more important for the level of activity in the ACC than the type of pain. In order to test this hypothesis we performed a post-hoc analysis in which the rCBF was regressed on the reported pain intensity ratings (irrespective if it refers to spontaneous pain or induced allodynia) across the rest and allodynia conditions, i.e. we used the reported total pain intensity as a covariate of interest in the general linear model. The results of the linear regression showed several significant activation foci, i.e. covariations between the total pain rating and the $\mathrm{rCBF}$, in the ACC $([\mathrm{x}, \mathrm{y}, \mathrm{z}]=[2,6,40], Z$-score $=3.32 ;[\mathrm{x}, \mathrm{y}, \mathrm{z}]=[-6,18,24]$, $Z$-score $=3.34 ;[\mathrm{x}, \mathrm{y}, \mathrm{z}]=[-4,-16,44], Z$-score $=4.87)$. This is consistent with the previously observed significant regressions and suggests that the ACC maintains the previously observed pattern of response to the overall perceived pain, but that inhomogeneities in spontaneous pain and also in the induced pain response may obscure effects unless appropriately accounted for. Similarly, there was a covariation between the pain intensity rating and the rCBF in the ipsilateral anterior insula $([x, y, z]=[28,18,12]$, $Z$-score $=4.1$ ) and in the contralateral anterior insula (nonsignificant tendency, $[x, y, z]=-32,6,4, Z$-score $=2.21$ ). Hence, there seems to be a covariation between subjective pain intensity rating and $\mathrm{rCBF}$ also for other areas of the medial pain system. In addition, it should be noted that the results for the lateral pain system were similar with the results previously described above.

A decrease was also observed in the inferior part of the ACC in the contrast Contralateral touch vs. Allodynia. This region of the ACC is involved in attention and the observed decrease may represent altered attention-dependent activity (Hsieh et al., 1995a). This finding is in line with the study of tactile allodynia after Wallenberg infarct (Peyron et al., 1998).

PAG is involved in behavioral and autonomic emotional responses during noxious stimulation (Carrive, 1993; LeDoux, 1993) and has been activated in experimental traumatic pain (Hsieh et al., 1995b). In the present study, an increased activation in the brainstem/PAG was observed during the allodynic state, which was not unexpected given the high intensity, the nature of the experienced pain and the increased heart rate during this state.

\section{Conclusions}

In this study of dynamic mechanical allodynia in patients with mononeuropathy, an extensive activation of the lateral pain system was observed. The activation in the somatotopic projection of the leg in S1 was significantly more expressed during allodynia than during non-painful touch. Bilateral activations were observed in the lateral pain system. Also, the activity of the medial pain system covaried positively to pain intensity ratings. This activation pattern contrasts to previous studies of ongoing spontaneous neuropathic pain where no increased activity of the lateral pain system was observed. Finally, an extensive pattern of deactivation was found during the allodynic state, which may represent attention-based inhibitions and central coping modulations during a severe, but well-known painful situation.

\section{Acknowledgements}

This work was supported by grants from the Swedish Medical Research Council (8276), the Karolinska Institute, the Swedish Medical Association, and the Knut and Alice Wallenberg foundation. Special thanks to Ellenor Andersson, Monica Serrander, Gustav von Heine, Göran Printz, Walter Pulka and Peter Söderholm for technical and administrative support.

\section{References}

Albe-Fessard D, Berkley KJ, Kruger L, Ralston HJ, Willis WD. Diencephalic mechanisms of pain sensation. Brain Res Rev 1985;9:217-296.

Andersson JLR, Lilja A, Hartvig P, Långström B, Gordh T, Handwerker H, Torebjörk E. Somatotopic organization along the central sulcus, for pain localization in humans, as revealed by positron emission tomography. Exp Brain Res 1997;117:192-199.

Apkarian AV. Functional imaging of pain: new insights regarding the role of the cerebral cortex in human pain perception. Semin Neurosci 1995; 7:279-293.

Apkarian AV, Shi T. Squirrel monkey lateral thalamus. Somatic nociresponsive neurons and their relation to spinothalamic terminals, J Neurosci 1994;14:6779-6795.

Apkarian AV, Stea RA, Manglos SH, Szeverenyi NM, King RB, Thomas FD. Persistent pain inhibits contralateral sosmatosensory cortical activity in humans. Neurosci. Lett 1992;140:141-147.

Bennett GJ. Neuropathic pain, R.a.W. In: Melzack PD, editor. Textbook of Pain, Edinburgh: Churchill Livingstone, 1994. pp. 201-224.

Bergström M, Boethius J, Eriksson L, Greitz T, Ribbe T, Widén L. Head fixation device for reproducible position alignment in transmission CT and positron emission tomography. J Comput Assist Tomogr 1981;5:136-141.

Berridge MS, Cassidy EH, Terris AH. A routine, automated synthesis of 
oxygen-15-labeled butanol for positron tomography. J Nucl Med 1990;31:1727-1731.

Blakemore SJ, Rees G, Frith CD. How do we predict the consequences of our actions? A functional imaging study. Neuropsychologia 1998;36:521529.

Burton H, Videen TO, Raichle ME. Tactile-vibration-activated foci in insular and parietal-opercular cortex studied with positron emission tomography: mapping the second somatosensory area in humans. Somatosens Mot Res 1993;10:297-308.

Carrive $P$. The periaqueductal gray and defensive behavior: functional representation and neuronal organization. Behav Brain Res 1993;58:27-47.

Casey KL, Minoshima S, Berger KL, Koeppe RA, Morrow TJ, Frey KA. Positron emission tomography analysis of cerebral structures activated specifically by repetitive noxious heat stimuli. J Neurophysiol 1994;71:802-807.

Casey KL, Minoshima S, Morrow TJ, Koeppe RA. Comparison of human cerebral activation patterns during cutaneous warmth, heat pain, and deep cold pain. J Neurophysiol 1996;76:571-581.

Chung JM, Lee KH, Surmeier DJ, Sorkin LS, Kim J, Willis WD. Response characteristics of neurons in the ventral posterior lateral nucleus of the monkey thalamus. J Neurophysiol 1986;56:370-390.

Coghill RC, Talbot JD, Evans AC, Meyer E, Gjedde A, Bushnell MC, Duncan GH. Distributed processing of pain and vibration by the human brain. J Neurosci 1994;14:4095-4108.

Colebatch JG, Deiber MP, Passingham RE, Friston KJ, Frackowiak RSJ. Regional cerebral blood flow during voluntary arm and hand movements in human subjects. J Neurophysiol 1991;65:1392-1401.

Craig AD, Bushnell MC, Zhang ET, Blomqvist A. A thalamic nucleus specific for pain and temperature sensation. Nature 1994;372:770-773.

Craig AD, Reiman EM, Evans A, Bushnell MC. Functional imaging of an illusion of pain. Nature 1996;384:258-260.

Davis KD, Wood ML, Crawley AP, Mikulis DJ. fMRI of human somatosensory and cingulate cortex during painful electrical nerve stimulation. NeuroReport 1995;7:321-325.

Davis KD, Taylor SJ, Crawley AP, Wood ML, Mikulis DJ. Functional MRI of pain- and attention-related activations in the human cingulate cortex. J Neurophysiol 1997;77:3370-3380.

Deiber MP, Ibanez V, Sadato N, Hallett M. Cerebral structures participating in motor preparation in humans: a positron emission tomography study. J Neurophysiol 1996;75:233-247.

Derbyshire SWG, Jones AKP, Gyulai F, Clark S, Townsend D, Firestone LL. Pain processing during three levels of noxious stimualtion produces differential patterns of central activity. Pain 1997;73:431-445.

Dettmers C, Fink GR, Lemon RN, Stephan KM, Passingham RE, Silbersweig D, Holmes A, Ridding MC, Brooks DJ, Frackowiak RS. Relation between cerebral activity and force in the motor areas of the human brain. J Neurophysiol 1995;74:802-815.

Di Piero V, Jones AKP, Iannotti F, Powell M, Perani D, Lenzi GL, Frackowiak RSJ. Chronic pain: a PET study of the central effects of percutaneous high cervical cordotomy. Pain 1991;46:9-12.

Di Piero V, Ferracuti S, Sabatini U, Pantano P, Cruccu G, Lenzi GL. A cerebral blood flow study on tonic activation in man. Pain 1994;56:167173.

Dong WK, Salonen LD, Kawakami Y, Shiwaku T, Kaukoranta EM, Martin RF. Nociceptive responses of trigeminal neurons in S2-7b cortex of awake monkeys. Brain Res 1989;484:314-324.

Drevets WC, Burton H, Videen TO, Snyder AZ, Simpson JRJ, Raichle ME. Blood flow changes in human somatosensory cortex during anticipated stimulation. Nature 1995;373:249-252.

Fink GR, Frackowiak RS, Pietrzyk U, Passingham RE. Multiple nonprimary motor areas in the human cortex. J Neurophysiol 1997;77:2164-2174.

Fox PT, Burton H, Raichle ME. Mapping human somatosensory cortex with positron emission tomographgy. J Neurosurg 1987;67:34-43.

Friedman DP, Murray EA. Thalamic connectivity of the second somatosensory area and neighboring somatosensory fields of the lateral sulcus of the macaque. J Comp Neurol 1986;252:348-373.
Friston KJ, Holmes AP, Worsley KJ, Poline JP, Frackowiak RSJ. Statistical parametric maps in functional imaging: a general linear approach. Hum Brain Mapp 1995;2:189-210.

Ghatan PH, Hsieh JC, Wirsén-Meurling A, Wrendling R, Eriksson L, Stone-Elander S, Levander S, Ingvar M. Brain activation induced by the perceptual maze test: A PET study of cognitive performance. Neuroimage 1995;2:112-124.

Ghatan PH, Hsieh JC, Petersson KM, Stone-Elander S, Ingvar M. Coexistence of attention-based facilitation and inhibition in the human cortex. Neuroimage 1998;7:23-29.

Gracely RH, Lynch SA, Bennett GJ. Painful neuropathy: altered central processing maintained dynamically by peripheral input. Pain 1992;51:175-194.

Greenspan JD, Winfield JA. Reversible pain and tactile deficits associated with a cerebral tumor compressing the posterior insula and parietal operculum. Pain 1992;50:29-39.

Greitz T, Bohm C, Holte S, Eriksson L. A computerized brain atlas: construction, anatomical content and some applications. J Comput Assist Tomogr 1991;15:26-38.

Hansson P. Possibilities and potential pitfalls of combined bedside and quantitative somatosensory analysis in pain patients. In: Boivie J, Hansson $\mathrm{P}$, Lindblom U, editors. Touch, temeprature, and pain in health and disease: mechanisms and assessements, vol. 3. Seattle: IASP Press, 1994. pp. 113-132.

Hansson P, Kinnman E. Unmasking mechanisms of peripheral neurpathic pain in a clinical perspective. Pain Rev. 1996;3:272-292.

Haxby JV, Horwitz B, Ungerleider LG, Maisog JM, Pietrini P, Grady CL. The functional organization of human extrastriate cortex: A PET-rCBF study of selective attention to faces and locations. J Neurosci 1994; 14:6336-6353.

Hsieh JC. Central processing of pain; Functional brain imaging studies with PET 91, Stockholm: Karolinska Institute, 1995.

Hsieh JC, Hägermark Ö, Ståhle-Bäckdahl M, Ericson K, Eriksson L, StoneElander S, Ingvar M. Urge to scratch represented in the human cerebral cortex during itch. J Neurophysiol 1994;72:3004-3008.

Hsieh JC, Belfrage M, Stone-Elander S, Hansson P, Ingvar M. Central representation of chronic ongoing neuropathic pain studied by positron emission tomography. Pain 1995a;63:225-236.

Hsieh JC, Ståhle-Bäckdahl M, Hägermark Ö, Stone-Elander S, Rosenqvist G, Ingvar M. Traumatic nociceptive pain activates the hypothalamus and the periaqueductal gray: a positron emission tomography study. Pain 1995b;64:303-314.

Iadarola MJ, Max MB, Berman KF, Byas-Smith MG, Coghill RC, Gracely $\mathrm{RH}$, Bennett GJ. Unilateral decrease in thalamic activity observed with positron emission tomography in patients with chronic neuropathic pain. Pain 1995;63:55-64.

Iadarola MJ, Berman KF, Zeffiro TA, Byas-Smith MG, Gracely RH, Max MB, Bennett GJ. Neural activation during acute capsaicin-evoked pain and allodynia assessed with PET. Brain 1998;121:931-947.

Ingvar M, Eriksson L, Greitz T, Stone-Elander S, Dahlbom M, Rosenqvist G, af Trampe P, von Euler CV. Methodological aspects of brain activation studies: cerebral blood flow determined with $\left[{ }^{15} \mathrm{O}\right]$ butanol and positron emission tomography. $\mathrm{J}$ Cereb Blood Flow Metab 1994;14:628-638.

Jones AKP, Brown WD, Friston KJ, Qi LY, Frackowiak RSJ. Cortical and subcortical localization of response to pain in man using positron emission tomography. Proc R Soc Lond 1991;244:39-44.

Kenshalo DRJ, Isensee O. Responses of primate S1 cortical neurons to noxious stimuli. J Neurophysiol 1983;50:1479-1496.

Kenshalo DRJ, Thomas DA, Dubner R. Primary somatosensory cortical lesion reduce the monkeys' ability to discriminate and detect noxious thermal stimulation. Soc Neurosci Abstr 1991;17:1206.

Kenshalo DRJ, Giesler GJ, Leonard RB, Willis WD. Responses of neurons in primate ventral posterior lateral nucleus to noxious stimuli. J Neurophysiol 1980;43:1594-1614.

LeDoux JE. Emotional memory systems in the brain. Behav Brain Res 1993;58:69-79. 
Mazziotta JC, Phelps ME, Carson RE, Kuhl DE. Tomographic mapping of human cerebral metabolism: auditory stimulation. Neurology 1982;32:921-937.

Melzack R, Casey KL. Sensory, motivational and central control determinants of pain: a new conceptual model. In: Kenshalo DR, editor. The skin senses, Springfield IL: CC Thomas, 1968. pp. 423-443.

Montgomery SA, Åsberg M. A new depression scale designated to be sensitive to change. Br. J. Psychiatry 1979;134:382-389.

Petersson KM, Elfgren C, Ingvar M. A dynamic role of the medial temporal lobe during retrieval of declarative memory in man. Neuroimage 1997;6:1-11.

Petrovic P, Ghatan PH, Petersson KM, Stone-Elander S, Ingvar M. Cognition alters pain related activity in the lateral pain system. Neuroimage 1998; 7:S437.

Peyron R, Garcia-Larrea L, Grégoire MC, Convers P, Lavenne F, Veyre L, Froment JC, Mauguière F, Michel D, Laurent B. Allodynia after lateralmedullary (Wallenberg) infarct; A PET study. Brain 1998;121:345356.

Price CJ, Wise RJS, Warburton EA, Moore CJ, Howard D, Patterson K, Frackowiak RSJ, Friston KJ. Hearing and saying; The functional neuroanatomy of auditory word processing. Brain 1996;119:919-931.

Raichle ME. Food for thought. The metabolic and circulatory requirements of cognition. [Review: 79 references]. Ann NY Acad Sci 835 (1997) 373-85.

Raichle ME. Behind the scenes of functional brain imaging: a historical and physiological perspective. [Review: 86 references]. Proc Natl Acad Sci USA, 1998;95:765-772.

Rainville P, Duncan GH, Price DD, Carrier B, Bushnell MC. Pain affect encoded in human anterior cingulate but not somataosensory cortex. Science 1997;277:968-971.

Roberts TS, Akert K. Insular and opercular cortex and its thalamic projection in Macaca mulatta. Schweiz Arch Neurol Neurochir Psychiatr 1963;92:1-43.

Robinson CJ, Burton H. Somatic submodality distribution within the second somatosensory (S2) 7b, retroinsular, postauditory, and granular insular cortical areas of M. fascicularis. J Comp Neurol 1980a;192:93108.

Robinson CJ, Burton H. Somatotopographic organization in the second somatosensory area of m. fascicularis. J Comp Neurol 1980b;192:4367.

Shulman GL, Corbetta M, Buckner RL, Raichle ME, Fiez JA, Miezin FM, Petersen SE. Top-down modulation of early sensory cortex. Cereb Cortex 1997;7:193-206.

Silverman DH, Munakata JA, Ennes H, Mandelkern MA, Hoh CK, Mayer EA. Regional cerebral activity in normal and pathological perception of visceral pain. Gastroenterology 1997;112:64-72.

Squire LR, Zola SM. Structure and function of declarative and nondeclarative memory systems. Proc Natl Acad Sci USA 1996;93:13515-13522.

Stephan KM, Fink GR, Passingham RE, Silbersweig D, Ceballos-Baumann AO, Frith CD, Frackowiak RS. Functional anatomy of the mental representation of upper extremity movements in healthy subjects. J. Neurophysiol 1995;73:373-386.

Talairach J, Tournoux P. Co-planar stereotaxic atlas of the human brain, Stuttgart: George Thieme Verlag, 1988.

Talbot JD, Marrett S, Evans AC, Meyer E, Bushnell MC, Duncan GH. Multiple representations of pain in human cerebral cortex. Science 1991;25:1355-1358.

Talbot JD, Villemure JG, Bushnell MC, Duncan GH. Evaluation of pain perception after anterior capsulotomy: a case report. Somatosens Mot Res 1995;12:115-126.

Ungerleider LG, Haxby JV. 'What' and 'where' in the human brain. Curr Opin Neurobiol 1994;4:157-165.

Vogt BA, Sikes RW, Vogt LJ. Anterior cingulate cortex and the medial pain system. In: Vogt BA, Gabriel M, editors. Neurobiology of cingulate cortex and limbic thalamus: a comprehensive Handbook, Boston, MA: Birkhäuser, 1993. pp. 313-344.

Vogt BA, Derbyshire S, Jones AKP. Pain processing in four regions of human cingulate cortex localized with co-registered PET and MR imaging. Eur J Neurosci 1996;8:1461-1473.

Weiller C, Juptner M, Fellows S, Rijntjes M, Leonhardt G, Kiebel S, Muller S, Diener HC, Thilmann AF. Brain representation of active and passive movements. Neuroimage 1996;4:105-110.

Wienhard K, Dahlbom M, Eriksson L, Michel C, Bruckbauer T, Pietrzyk U, Heiss WD. The ECAT EXACT HR: Performance of a new high resolution positron scanner. J Comput Assist Tomogr 1994;18:110-118.

Willis WDJ. Cold, pain and the brain, Nature 1995;373:19-20. 